\title{
De um tema a um problema de pesquisa: implicações a partir da perspectiva construcionista para a investigação no campo da educação e das artes visuais
}

\section{Resumo}

Este texto introduz ideias acerca da perspectiva construcionista e possíveis contribuições para a pesquisa no campo das artes visuais e seus entornos educativos. Com base nesta argumentação, propõe-se abordar estratégias metodológicas de caráter interpretativo para transitar de um tema de interesse à configuração de um projeto de pesquisa no âmbito acadêmico no que concerne às relações com as práticas culturais e de significação. Kenneth Gergen, Jerome Bruner e Max Van Manen são os principais autores que contribuem neste contexto para pensar sobre a forma como cada sujeito desenvolve aspectos constituintes de sua subjetividade, como atribui sentido às suas experiências cotidianas e suas relações com a construção do conhecimento.

Palavras-chave: Pesquisa, construcionismo social, educação, artes visuais.

\section{From the theme to the research problem: implications for the constructionist perspective in the visual arts and education research}

\begin{abstract}
This text introduces ideas about constructionist perspective and possible contributions to research in the field of visual arts and their educational environments. Based on this argument, proposes to address methodological strategies interpretative character to move from a topic of interest to the setting of a research project by academics with regard to relations with the cultural and practical significance. Kenneth Gergen, Jerome Bruner and Max Van Manen are contributing authors in this context to think about how each person develops constituent aspects of his subjectivity as assign meaning to their everyday experiences and their relationships with the construction of knowledge.
\end{abstract}

Keywords: research, social constructionism, education, visual arts.

\section{Introdução}

Quando nos colocamos diante da necessidade de definir o tema de investigação e seus desdobramentos no contexto acadêmico - implicações conceituais, perspectivas e abordagens metodológicas, bem como a escolha por autores que possam dialogar com nossas ideias - em geral passamos por um momento de crise até definirmos um caminho diante de tantas possibilidades. Mas ao contrário do que prevê o senso comum, momentos de crise são produtivos, pois sugerem que o caminho percorrido ou projetado necessita ser revisado, repensado a partir de um amplo cenário de possibilidades. De 
acordo com o sociólogo holandês Max van Manen (2003: 23) "investigar significa questionar o modo ao qual experimentamos o mundo, a querer conhecer o mundo em que vivemos a partir de nossa qualidade de seres humanos". Neste sentido, ao iniciarmos um processo investigativo somos movidos por um desejo de reinterpretar algo, de atribuir significado antes impensado, de propor um trajeto que talvez ainda não tenha sido cursado.

Ainda de acordo com Van Manen (2003: 24) "ao investigar questionamos os segredos mais ocultos do mundo, que o constituem e que o fazem que seja mundo para nós". Portanto, investigar consiste em um ato de preocupação: queremos conhecer aquilo que nos aguça a curiosidade diante de uma situação ainda inusitada, carente de um olhar desconfiado de nossa parte.

Desta forma, fomentar a reflexão e o debate acerca das problemáticas contemporâneas em torno das imagens e suas representações vinculadas nos mais variados contextos culturais e sociais de produção e distribuição, nos oferecem a chance de revisitarmos nossas próprias crenças, valores e formas de compreender o mundo e nossas relações de aprendizagem. Neste sentido, ao nos posicionamos a partir de perspectivas que dialogam sob o enfoque construcionista nos possibilita criar contra discursos, transgredir ideias enraizadas, propor múltiplas abordagens, pois, como bem sabemos, existem infinitas alternativas de pensar e propor a pesquisa no âmbito acadêmico e não unicamente atrelado às heranças do positivismo científico pautado pelo método científico. Sobretudo no que tange às imagens produzidas e veiculadas pela cultura contemporânea que constroem e modelam nossas práticas de ver e nos relacionarmos.

Partindo da abordagem construcionista ver não consiste em uma ação individual, mas caracteriza-se, sobretudo, por uma prática social contingente: nossas referências culturais e imagéticas não são absolutamente nossas, uma vez que estão atreladas às comunidades discursivas às quais nos vemos implicados (GERGEN, 2006). Além disso, as ideias que constroem nosso imaginário não correspondem unicamente a uma combinação de elementos visuais composta por linhas, planos e luminosidade, mas por aquilo que estabelece como valor. Assim sendo, construir processos mestiços, alternativos, variados, híbridos, bricoleurs que potencializem outros sentidos e também outras formas de fazer pesquisa nos acenam a possibilidade de sermos autores de nossos próprios percursos no âmbito da aprendizagem. Desta forma, a perspectiva 
construcionista apresenta-se como mosaico de fundamentações ontológicas, epistemológicas e metodológicas que propõe dialogar acerca da forma como concebemos o mundo e a realidade social e localmente construídas, levando em consideração os aspectos subjetivos e culturais que constroem o sujeito ( HOLSTEIN; GUBRIUM: 2008).

A partir destas ideias iniciais, o convite lançado neste texto busca situar a pesquisa acadêmica em um campo provisório, passível de transformação e reconfiguração, pois, uma vez que a realidade é concebida a partir da negociação entre sujeitos, mediante sua contingência, o mundo social em que vivemos bem como suas regras, hierarquias e complexidades estão inevitavelmente atreladas às interpretações da mente humana. Da mesma forma, partilhar ideias que contribuem para estimular o olhar crítico e provocativo, bem como pensar reflexivamente sobre as narrativas conduzidas pela cultura dominante - uma vez que estamos sujeitos às decisões coletivas - nos sugere colocar em marcha estratégias didáticas de aprendizagem no âmbito da pesquisa mobilizadas a partir da curiosidade inventiva.

\section{Contingências da investigação construcionista}

Argumentar que nossas concepções sobre o que pode ser considerado real e verdadeiro são construções culturais, históricas e sociais, e que, portanto, são relativas, pode ser o primeiro passo para iniciar uma discussão a respeito do que trata a perspectiva construcionista. Em seguida, pode-se pensar que em contornos complexos, como aqueles que buscam explicar as dinâmicas da subjetividade humana, bem como situações quotidianas, sugere que estamos sujeitos a processos seletivos que, em detrimento de outros, delineiam nossas possibilidades de ser e existir. A própria ideia moderna sustentada pelos âmbitos cultural e social que defendia a racionalidade científica como instância primeira para pautar determinadas formas de pensamento e justificar, por exemplo, o contexto escolar como única via de acesso ao conhecimento - propondo a aquisição de conhecimentos a partir de um ideário dualista, objetivo, mensurável - que ocorreria apenas com a intervenção do especialista pode ser deixada à margem se optarmos por um marco construcionista.

Diferentemente de uma concepção fixa, o construcionismo social se apresenta como uma não-teoria, que busca deslocar as noções de verdade e de tudo aquilo que 
entendemos como real e verdadeiro a partir de uma visão crítica, flexível e questionadora. Propõe também, refletir principalmente sobre as construções sociais que permeiam a vida diária a partir das relações entre cultura, ideologia, poder, subjetividade, imaginário e representação social no que concerne o entendimento que elaboramos do mundo e suas relações com as práticas culturais.

Este enfoque que teve sua gênese em meados dos anos 1960 na esfera das ciências sociais com os estudos de Peter Berger e Thomas Luckmann (The Social Construction of Reality, 1966) nos apresenta atualmente significativas contribuições para reconceituarmos a pesquisa acadêmica:

O construcionismo procura superar esta dualidade objeto-sujeito desenvolvendo uma teoria alternativa do funcionamento da ciência e desafiando a ideia de conhecimento como representação mental. O construcionismo sustenta que o conhecimento não é algo que a gente possui na cabeça, mas algo que a gente constrói coletivamente, onde a linguagem é essencialmente uma atividade partilhada. (GERGEN, 2006: 54).

A partir destas referências, podemos propor que nossos processos investigativos, assim como nossas experiências quotidianas estão atreladas aos significados humanos cunhados pela linguagem e que envolvem processos de negociação - oriundos de séculos de construção, seleção, legitimação e institucionalização - e, da mesma forma, de manutenção de posições de poder e igualmente com as dinâmicas da vida social e coletiva, base da elaboração das sociedades.

Portanto, uma investigação a partir da perspectiva construcionista no âmbito das ciências sociais, questiona os fenômenos que constroem a realidade social, que configuram e atribuem sentido às práticas de ver e ser visto, compreender e ser compreendido. A partir deste posicionamento, o mundo em que vivemos bem como os papéis que ocupamos não são evidentes, pois estão atrelados às relações de poder, de negociação que ao longo de infinitos processos de elaboração configuram e delimitam condutas. É importante pensarmos que, apesar do risco de cairmos em um relativismo radical, não podemos deixar de pensar que tudo aquilo com o qual nos relacionamos, foi, em algum dado momento, identificado, justificado, nomeado, catalogado e propagado. Para Tomás Ibáñez (2001) questionar os processos ordinários que regem a vida quotidiana e os 
variados artifícios que dotam de sentido o senso comum, tais como o sentimento de pertença e as noções de realidade, verdade e ciência, podem ser um ponto de partida para a formação de investigadores construcionistas.

\begin{abstract}
Abandonar a crença de que o conhecimento válido, ou adequado, é adequado precisamente porque representa corretamente aquilo sobre o qual versa, é um passo obrigatório para desembocar sobre uma perspectiva construcionista. Este passo conduz a situar o conhecimento científico como conhecimento simplesmente relativo, mesmo que seja apenas em términos de relativismo conceitual. 0 conhecimento científico recorre a conceitos e categorias que são estritamente convencionais, isto é, que não representam nada além daquilo que já havíamos decidido que representariam. (IBÁÑEZ, 2001: 253)
\end{abstract}

Segundo o autor, o sofista Protágoras (490 a.C. - 415 a.C.) já argumentava que à medida que o sujeito ampliava noções de si mesmo, o fazia ao tomar-se como medida de todas as coisas, ou seja, que só seria possível reconhecer, nomear e tornar familiar a partir das relações que estabeleceria a partir de si, de suas referências anteriormente apreendidas. Ou seja, desejos, ações e aspirações estão pautados pelo universo simbólico com o qual tangenciamos e não estão restritos aos aspectos biológicos em primeira instância. Segundo Bruner (1991: 37) "corresponde à cultura e à busca por significado que constituem as mãos que moldam, mesmo que diante das limitações biológicas, pois a cultura tem inclusive o poder de abrandar tais limitações". O que evidencia também que as conformações diárias dependem fundamentalmente dos conceitos e significados elaborados coletivamente, do domínio discursivo que possibilita que o universo simbólico seja aceito, compreendido e reinterpretado. Vivemos entrelaçados por significados oriundos do imaginário coletivo mediados pelas representações que nos são acessíveis e que possibilitam sua compreensão e difusão. Neste sentido, as concepções culturais que cercam o cenário da pesquisa científica e/ou acadêmica, merecem reconhecer que o conhecimento é transacional, que resulta de processos interpretativos, uma vez que resultados são criações dos sujeitos implicados em um íntimo processo de elaboração e conexão (IBÁÑEZ, 2001).

Portanto, questionar a pesquisa e a construção do conhecimento envolve a articulação de saberes híbridos como os percursos rizomáticos sugeridos por Deleuze e Guattari (1995) que estabelecem conexões e produzem novas relações; que promovem o questionamento, a pensar não somente sobre aquilo que é explicitado como valor, 
verdade ou realidade, mas também àquilo que permanece fora das apreensões que compreendem a ação humana. Assim sendo, a perspectiva construcionista nos instiga a pensar as noções da centralidade dos saberes em términos de autenticidade, legitimidade e relevância ao conferir um caráter relativista em relação ao contexto cultural de produção e circulação do conhecimento científico/acadêmico.

Neste sentido, o construcionismo convida a adotar uma atitude de curiosidade infinita, a nos mantermos constantemente abertos ao que cada tradição traz de riquezas e combinações impensadas. Se admitimos que as realidades de hoje dependem dos acordos que alcancemos hoje, ante nós abrem-se enormes possibilidades. Não estamos destinados a repetir o passado; a inovação através da colaboração abre perspectivas novas (GERGEN, 2006: 56).

Ainda no campo da investigação, este enfoque implica explorar os saberes e suas articulações que potencializados a partir da prática investigativa, aponta em direção à compreensão interpretativa, ficcional - ainda que com caráter verosímil. Nosso conhecimento "por conseguinte, converte-se em conhecimento culturado, que não pode definir-se desprovido de um sistema de sentido articulado culturalmente" (BRUNER, 1991: 38). O contexto acadêmico a partir desta ótica se desloca da perspectiva de construção de verdades pautadas por aplicação de métodos e formulação de resultados para uma abordagem interpretativa, aberta, provisória elaborada a partir de pistas, de alternativas abertas como resposta.

\section{Algumas pistas para iniciarmos uma pesquisa construcionista}

Quando narramos nossas experiências articuladas a partir da exploração investigativa colocando-as em relação com perspectivas teóricas, nos aproximamos de processos que articulam visões e repertórios conceituais que mobilizam percepções variadas a partir da prática de estabelecer relações. Como um rizoma, estes processos narrativos oriundos da experiência vivida acenam caminhos que utilizam-se da reflexividade inventiva como recurso para compreender onde nos situamos e quais são as lentes culturais que usamos, não apenas para visualizar, mas também para pensar os entremeios que são invisibilizados, que nos possibilitam ir além dos aspectos conceituais que são apresentados para pensar sobre aquilo que construímos como significado. 
Neste sentido, pesquisas no campo da arte e da educação, aspiram provocar deslocamentos de verdades estanques para uma compreensão flutuante daquilo que define modos de ser e estar no mundo. Adquire também a função de desencadear processos de indagação, pois, em lugar de reduzir ou ilustrar a compreensão do mundo, propõe a mobilidade dos saberes, deslocamentos perceptivos, investigação dos fatos cotidianos à luz do questionamento frente às verdades institucionalizadas.

Para tanto, é possível que uma investigação construcionista inicie com ênfase nas perguntas que seleciona: sua implicação começa com a definição por perguntas com as quais avançar, porém refletindo com mesma intensidade sobre àquelas que ficam fora. De acordo com Kenneth Gergen (1996), em uma pesquisa de cunho construcionista, não se trata de descobrir algo, mas suas possíveis conexões, as redes que o relacionam, que constroem uma intencionalidade, sem deixar de lado as redes atreladas ao campo discursivo da linguagem que o potencializa. Desta maneira, ao investigar as próprias experiências entrelaçadas com o tema investigado, permitimo-nos avançar o campo reflexivo e relacional acerca dos conceitos veiculados e legitimados pela estrutura dominante, o que pressupõe um olhar atento à relatividade existente nas relações. O que torna as experiências oriundas do processo investigativo relatos que situam formas de olhar diante de determinados marcadores sociais/culturais em relação com posições discursivas que articulam estas relações.

Para tanto, necessitamos de um ponto de partida em que nos coloquemos em uma posição de instabilidade, de suspeita. Caso contrário, estamos adentrando por uma paisagem já conhecida, previsível e que certamente não irá surpreender ou embrenharnos por terrenos movediços. Daí a importância de iniciarmos a partir de um tema que nos mobilize onde apontamos palavras-chave conectadas àquilo que já sabemos e também àquilo que gostaríamos de saber mais (as nossas perguntas): isto é, àquilo que suspeitamos que poderemos descobrir ao longo da jornada. Ter um problema de pesquisa pode ser entendido como quando nos vemos diante de um desafio em que temos que propor um plano de ação que envolve conhecimentos prévios (temas de interesse, experiências vividas, referências conceituais, bibliográficas, conhecimento de outras pesquisas), um planejamento estratégico (perguntas, procedimentos metodológicos, etapas, abordagens investigativas) e alguns possíveis lugares de chegada que nos possibilitem situar nosso campo investigativo (marco conceitual, pistas que possam dar conta das perguntas). 
Neste interim, vale ressaltar que um trabalho escrito a partir de abordagens interpretativas, biográficas e/ou narrativas, são oriundas de natureza complexa: parte de uma descrição e amplia para uma reflexão que dialoga com o caminho percorrido, o que corresponde a uma interpretação, uma "ficção" possível de ser credibilizada. No campo das artes visuais, por exemplo, um texto não poderia estar preso às limitações da linguagem simbólica, pois parte de uma estrutura investigativa que busca dar conta daquilo que atravessa experiências de produção, visualização, interpretação e construção de conhecimento na esfera artística. Extrapola os limites de códigos pois engendra processos emocionais, afetivos, sensoriais, táteis, experiências caracterísiticas da manifestação artística que se manifesta, sobretudo, no âmbito da subjetividade.

Falar, descrever, interpretar, conceituar o próprio processo formativo implica levar em consideração diversificados, amplos, complexos, fragmentários e transitórios aspectos que envolvem a escrita autobiográfica para não cair em uma narração autocomplacente apenas. Prima pela construção de um tecido provocativo que possibilite tanto a quem a produz, como ao leitor, fazer conexões mais amplas, entre o universo subjetivo e o campo das representações sociais/coletivas. Enquanto utilizamos a perspectiva construcionista de cunho autobiográfica para explorar o terreno investigativo e seus desdobramentos de escrita, é possível promover diálogos significativos ao examinar experiências próprias provocadas a partir da indagação.

Os eventos narrativos que constroem a história de vida produzem uma grande quantidade de relatos que se relacionam e possibilitam seu desenvolvimento. De acordo com Brunner (1991: 119) o 'eu, quando narra, não se limita a contar, mas busca justificar' de forma que os feitos inscritos nas estórias pessoais funcionem como convite a explorar as formas como os sujeitos dão sentido à condição humana em relação com os demais. O impulso de descrever e nomear compreende uma atividade própria da natureza humana que recorre à narração da própria vida como uma forma de dar sentido a si mesmo, uma vez que "toda voz individual, como nos ensina Bajtin, está abstraída de um diálogo" (BRUNER, 1991: 14).

E tendo em vista que somos aquilo que podemos 'ver', 'sentir', e também 'entender', ver se apresenta como prática. Ver a importância em uma determinada situação nos coloca no acontecimento, nos faz formar parte. 
Escrever, escrever de verdade, consiste em ser autor, isto é, o exercício da autoridade: poder que, assim sendo, é autor do nosso existir pessoal e da forma. Escrever nos exercita o sentido de que nos proporciona um acontecimento expresso que agora podemos conduzir à ação ou em nossas próprias representações da vida diária. (VAN MANEN, 2003: 146)

Portanto, o eu investigador está no centro do processo formativo - a partir desta ótica, não há dicotomia entre aquele que investiga e aquilo que é investigado, mas ambos se complementam: investigo enquanto me construo/descubro como investigador - há uma simbiose, mobilidade produtiva que articula saberes oriundos de diversas instâncias, desde o coletivo ao individual, e vice-versa, de forma não hierarquizada. Fazer pesquisa, a partir deste enfoque corresponde a uma prática que não pode ser ensinada mas experienciada, descoberta, vivida.

\section{A relação biográfico-narrativa como um ponto central para o construcionismo}

Legamos do Positivismo a ideia de seguir métodos, aplicar etapas processuais estanques e muitas vezes descontextualizadas, ou ainda, que estuda as relações humanas negligenciando sua complexidade social, histórica e cultural. É comum ainda encontrarmos trabalhos acadêmicos com vocábulos duros ao tratar de questões complexas, subjetivas e oriundas dos campos das ciências sociais como se fosse possível extrair dados das experiências humanas destituídas de seu contexto de origem para serem dissecados em um asseado laboratório. Talvez esta concepção de pesquisa vinculada a terrenos áridos e pouco relativos tenha sua gênese nos anos escolares na escola tradicional onde aprendemos durante as aulas que os livros-texto estão constituídos de verdades e não deixam margem para pensarmos nós mesmos como autores.

A partir destas ideias, podemos propor que um relato de caráter autobiográfico que conecta experiências particulares e profissionais dialoga com o que argumenta Bruner (1991: 102) sobre o fato de que 'somos uma colônia de Eus Possíveis, entre os quais se encontram temidos e desejados, todos aglomerados para tomar posse de um Eu atual'. Da mesma forma, trata de um eu que compreende a estrutura familiar, redes de amigos e companheiros de trabalho oriundos das experiências diárias que encaram as experiências vividas como fontes de conhecimento, ou seja, um eu construído a partir de múltiplas subjetividades 
Em um processo reflexivo emerge outra consideração: o/a investigador/a se manifesta na medida em que se relaciona com objetos e sujeitos em sua atividade, e o que surge a partir desta relação é produto que em parte está predeterminado pela natureza dos objetos e sujeitos sociais (construções sócio-históricas), tem um componente imprescindível e criativo, produto de elementos contingentes, indexais e circunstanciais do contexto onde acontece a ação (IÑIGUEZ, 2003: 15)

Consiste, desse modo, na busca por responder às questões genuinamente particulares frente ao sentimento de insatisfação diante do mundo tal e qual o experimentamos. Diante das infinitas possibilidades de recombinar, reelaborar os espaços com os quais nos implicamos diariamente, em que sentido o que propomos a partir de nossos próprios processos e experiências podem servir para delinear uma pesquisa?

Contudo, iniciar a escrita de um artigo acadêmico desde um relato autobiográfico sugerenos que exploremos as relações entre um eu que se coloca diante da pesquisa de maneira transitória, fragmentada e relacional. Os sistemas de representação mediados pela cultura conferem aos sujeitos contemporâneos um ideário aberto, flexível e que busca abarcar a complexidade da diferença.

O conhecimento de uma 'pessoa' não se encontra simplesmente em sua cabeça, em um 'solo de persona', mas também nas anotações que tomou em seus cadernos, nos livros com passagens destacadas que mantemos em nossas estantes, nos manuais que aprendemos a manusear, nas fontes de informação que conectamos em nossos computadores, a partir dos amigos que buscamos com frequência nos aconselhar, e assim sucessivamente e quase infinitamente (BRUNNER, 1991: 106-107).

Para Bruner (1991: 83), no âmbito da narratologia 'uma narrativa não pode existir sem uma voz que a conte', que opere em nível de discurso com a finalidade de dominar os léxicos gramaticais que são necessários para dar conta da experiência vivida. Desta forma, pensar sobre quem narra e a partir de onde articula sua voz, possibilita articular quais são as posições ideológicas, políticas, sociais e culturais que sustenta e que atravessam seu relato, assim como a forma de relatar. 
Existe algo curioso na autobiografia. É um relato construído por um narrador em um aqui e um agora por um protagonista que leva seu nome e que existia em um ali e um então, e a história termina em um presente, quando o protagonista se funde com o narrador (BRUNER, 1991: 119)

Neste sentido, as formas de conhecimento geradas a partir da experiência investigativa mobilizadas por meio de uma escrita que se nutre da experiência versada, nas palavras de Max Van Manen "buscam compreender as estruturas de significado oriundas das experiências vividas" (2003: 22). Para o autor a pesquisa "necessita da hermenêutica para outorgar um sentido interpretativo aos fenômenos do mundo e da vida com a finalidade de determinar a importância das situações e relações com a vida cotidiana" (VAN MANEN, 2003: 20). Sobre este aspecto, Hernández e Rifá (2011: 07) explicitam que uma investigação de caráter autobiográfico não restringe-se apenas em narrar as experiências de forma cronológica sobre si mesmo, mas a partir de si, elaborando um tecido provocativo que busca estabelecer relações entre o relato subjetivo e a complexidade social ao qual o sujeito se vê implicado. Pressupõe questionar igualmente a relação objetividade/subjetividade, legados do positivismo que ainda exercem grande força sobre as investigações no âmbito das ciências sociais.

\section{Mobilizar saberes para aprender com sentido: explorando o conceito de I/ Mediações nas Artes Visuais e Entornos Educativos}

I/Mediações ${ }^{1}$ nas artes visuais e na esfera educativa carrega duplo sentido: mediar processos de subjetivação e promover diálogos entre arte e investigação visual/social, entre arte e produção teórica, entre arte e processos de significação, entre arte e cotidianidade, entre arte e sociedade, entre arte e processos educativos. Mediação implica elaboração conectiva entorno dos artefatos visuais produzidos pela cultura sejam estes obras de arte ou não. Compreende os aspectos veiculados pela cultura visual que constroem e corporificam as relações. I/Mediações, portanto, compreende movimento, deslocamento entre visualizador e o que é visualizado. Configura-se também como elemento provocador, que auxilia nos processos de indagação diante de uma imagem e/ou artefato cultural/social. Neste sentido, i/mediações pode ser compreendido também como uma prática de mobilidade: prática que requer movimentar, reposicionar

\footnotetext{
${ }^{1}$ O termo I/Mediações é o ponto central de discussões realizadas pelo grupo de Estudos e pesquisas Artes Visuais e suas I/Mediações da Universidade Federal de Santa Maria, Centro de Artes e Letras. Um dos aspectos ao qual se detém as ações do grupo dizem respeito aos entornos educativos que são potencializados a partir da arte e seus possíveis desdobramentos na formação de artistas e professores de artes visuais.
} 
de um ponto em direção a outro(s). Em sua origem latina, a palavra mobilis implica mudar de lugar, colocar em movimento (movere). No âmbito educativo/formativo, mobilizar sugere possibilidades de ampliação, de conexão com outros ou novos saberes e aprendizagens.

O ponto de partida é sempre a partir de uma experiência anterior. Resultam acessíveis, complementárias, sequenciais para o sujeito que se sente envolvido por uma sucessão de experimentações. Implica posicionar-se como investigador que suspeita, descobre, reconstrói - mistura, sobrepõe, interfere. Para dar seguimento à investigação, a ruptura com a lógica formal é decisiva pois só será possível propor algo inusitado a si mesmo ao destituir-se das ideias previamente internalizadas a respeito do que é considerado válido academicamente nos mais variados âmbitos. Investigar e propor abordagens diferenciadas perpassa por um movimento de desaprender para reaprender destituído das concepções positivistas que herdamos de séculos passados.

o problema é que nossos conhecimentos prévios a partir do senso comum, nossas suposições, ideias e o conjunto de conhecimentos científicos existentes, nos predispõem a interpretar a natureza do fenômeno antes mesmo de que nos questionemos a importância da questão que pretendemos investigar (VAN MANEN, 2003: 67)

No que confere à práxis investigativa, pesquisar sugere problematizar, promover deslocamentos a partir do questionamento. O desafio é reativar a curiosidade infinita e o desejo constante de resignificar as próprias práticas, experimentar outras possibilidades e acionar outras formas de compreensão. Neste ideário, mobilidade constitui-se a partir do enfoque construcionista (GERGEN, 1996; IBÁÑEZ, 2001) e da perspectiva da educação da cultura visual (HERNÁNDEZ, 2007) para sugerir, suscitar e apontar possibilidades de diálogo, análise e reflexão acerca das narrativas visuais no campo das artes. Além disso, tomando como ponto de partida as imagens da cultura contemporânea como dispositivo para pensar/refletir sobre os processos que envolvem a constituição do sujeito. O termo i/mediação refere-se também àquilo que cerca, que aproxima-se do campo em evidência: está nas imediações, nas proximidades. É um termo fronteiriço onde as fronteiras são tênues ou inexistentes, diluídas. I/mediações, portanto, dizem respeito à tudo aquilo que pode promover diálogos profícuos a partir das relações entre os distintos saberes, de modo trans e intradisciplinares. 
Neste sentido, partir de um conjunto de perguntas mobilizadoras possibilta articular um roteiro de questionamentos que permitem que o sujeito investigador descubra seu próprio caminho metodológico: as perguntas mobilizadoras convidam a potencializar a ambiguidade, a discrepância, a complexidade dos campos social, político, ideológico e cultural, pois questionam vários aspectos que se relacionam com a pesquisa: Qual é o tema geral? Que perguntas poderiam buscar respostas a partir do tema? Qual é o principal argumento que mobiliza o desejo por adentrar em um terreno ainda desconhecido? Quais concepções culturais e ideológicas prevalecem sobre o tema investigado? Podemos estabelecer conexões/relações entre a ficção e a realidade a partir de um enfoque narrativo? Quais temas ou perguntas permanecem sem respostas? O que poderia ser potencializado a partir do tema? Como se relacionam os principais argumentos que norteiam o campo investigado? Como investigar o tema de interesse para encontrar o foco da pesquisa? Esta pesquisa é sobre o quê? Do que ela trata? O que pretende? Que diálogos são pretendidos provocar a partir desta produção? Como problematizar o tema para delimitar os caminhos investigativos? Quais são as concepções ideológicas sobre a pesquisa na contemporaneidade? Existem estruturas formais às quais uma pesquisa precisa estar submetida para adquirir o status científico digno de credibilidade? Como aparecem representadas as concepções de gênero e classe social em relação ao tema da pesquisa? Para quem está direcionada a pesquisa?

Ao final do processo, possivelmente surgirão algumas pistas (ainda flexíveis, instáveis, abertas) ao passo que evidenciar o que esta caminhada possibilitou aprender/descobrir revela um andamento produtivo. A pesquisa, em primeiro lugar, precisa fazer sentido ao investigador que ao mesmo tempo em que avança em seus desvelamentos, como constrói-se investigador. Suas ideias, concepções históricas, ideológicas, culturais e sociais participam não apenas da escrita, mas também das próprias experiências de vida. Não se prende apenas à descrição do que foi feito, mas parte de uma exposição e amplia para uma reflexão que dialoga com o caminho percorrido.

O fato de considerar as verdades sobre os saberes como construções sociais significa reconhecer que cada contexto cultural, cada tradição reclama para si mesma determinadas visões e entendimentos a respeito do mundo. Um aprender colaborativo e não transmissivo parte daquilo que pode servir a todos, que possibilita a cada um e cada uma encontrar seu próprio lugar no processo. 
Uma investigação no âmbito das ciências sociais (seja na arte ou campos afins) compreende os fenômenos da experiência humana a partir de muitos enfoques e perspectivas possíveis. Os elementos de negociação entre os diversos saberes oriundos da experiência, da vida vivida com o âmbito acadêmico oriundo do campo teórico, das reflexões construídas nos ambientes educativos e de socialização de saberes são também parte de uma estrutura que é narrativa, que perpassa tramas, tessituras, movimentos de ida e volta, de relação entre partes distintas mas que em algum momento se encontram. Durante o processo formativo/investigativo, o sujeito se vê implicado com o universo da cultura, da sociedade e da politica a partir das experiências relacionais que estabelece ao produzir algo.

Nossas primeiras aprendizagens como humanos acontecem dentro da cultura a qual nos vemos implicados: aprendemos a ser homens ou mulheres, absorvemos a lógica cultural, suas hierarquias, suas regras e valores a partir da observação, mas sobretudo a partir da experimentação e da linguagem. Também passamos por diversas etapas e papéis: aprendemos a nos relacionar como bebês, como crianças, adolescentes, jovens adultos, idosos, e em cada etapa, desenvolvemos formas de ver, relacionar, articular, falar, deslocar, sonhar, planejar, enfim, de compreender o mundo e a nós mesmos.

No que se refere à pesquisa em arte, ou em educação, igualmente as formas de compreensão e constituição do pensamento vão sendo alteradas na medida em que os sujeitos se desenvolvem fisiológica e cognitivamente - mediante o contexto. Daí vale dizer que aprendemos a investigar como crianças, passando à métodos mais elaborados à medida em que apreendemos formas de compreensão e representação, mediados pelo ímpeto investigativo. A partir deste ponto, iniciamos um processo que considero uma sequência de incômodos Individualmente ou coletivamente nos dedicamos a investigar nossos incômodos - podemos dizer que a pesquisa nasce de incômodos pessoais, do desejo de experiências inusitadas.

Perguntar algo de verdade significa interrogar sobre algo a partir da nossa existência, desde o centro de nosso ser. Inclusive projetos de investigação fenomenológica mais modestos nos requerem não propor uma pergunta que nos esqueçamos facilmente, mas algo que vivamos neste questionamento, que nos convertamos nela. (VAN MANEN, 2003: 63) 
Neste sentido, podemos questionar a partir daquilo que vivenciamos com intensidade, num imbricamento profundo e produtivo - ainda que seu produto seja a frustração. $O$ conflito, a imprevisibilidade e as recorrências são produtivas pois desencadeiam relações de aprendizagem não linear. A natureza deste processo investigativo pode ser associada a outras formas de constituição do próprio sujeito uma vez que investiga e propõe possibilidades abertas e flexíveis de resolução de problemas. Para o investigador construcionista quiçá o sentido de mobilidade que configura as perguntas mobilizadoras como proposta híbrida e transdisciplinária sugere abandonar a ideia central das bases do cientificismo em lugar de pedagogias culturais fluidas e contingentes.

\section{Algumas considerações}

É importante pensarmos que todos os métodos são invenções, que foram criados por alguém e legitimados por um grupo a partir de critérios específicos. Ter em conta a natureza exploratória e interpretativa do processo investigativo - relação com a perspectiva enfocada pelo bricoleur, por exemplo, que nas palavras de Kincheloe e Barry (2004) significa reconhecer que há uma multiplicidade de caminhos de natureza relacional com os quais podemos fazer uso durante um processo investigativo - nos possibilita fugir da ideia de um único método que pode ser aplicado de forma estanque para estudar um fenômeno. Aprendemos através do ato de estabelecer relações - o conhecimento não está em si mesmo, mas naquilo que é produzido a partir das conexões, dos diálogos estabelecidos (GERGEN, 1996).

O que podemos aprender a partir de nossas experiências investigativas? Talvez, a aguçar com vivacidade nossa curiosidade pueril: uma curiosidade sincera, ingênua, realmente interessada e livre de convencionalismos. Uma investigação no âmbito das artes visuais ou do campo educativo sob este enfoque nos ajuda a compreender os fenômenos da experiência humana a partir de muitos aspectos e perspectivas possíveis. Além disso, abarca os elementos de negociação entre os diversos saberes oriundos da experiência, da vivida no seio acadêmico proveniente do campo teórico, das reflexões construídas nos ambientes educativos e de socialização de saberes.

Como estabelecer relações entre o campo de interesse e o foco ou tema de um processo investigativo? Pensar qual o sentido deste tema/processo incita perceber que o problema 
surge a partir de algum incômodo, do desconforto, da sensação de que algo permanece fora do foco do olhar e que poderia ser revisto, reinterpretado. Talvez, o passo inicial seja começar por uma ideia em forma de pergunta: improvisar relações, conectar a outros argumentos, tecer algumas possibilidades.

Por vezes, nos deparamos com o óbvio e não saímos do lugar. A perspectiva construcionista defendida por Kenneth Gergen (1996), ao que parece, parte do óbvio, daquilo que está à nossa frente e que, articulados pelas lentes culturais/ ideológicas/ sociais/ históricas não nos permitem percebê-lo em sua particularidade. Muitas vezes o evidente está tão arraigado em nossas formas de perceber o universo à nossa volta que não nos possibilita múltiplas miradas. Daí a busca por uma ciência experimental, híbrida, fluida, ativa, processual: da mesma forma como são complexas as experiências humanas, também os processos de apreensão, compreensão e análise o são.

Decorrente disso, os caminhos que percorremos com intuito de compreendê-las, por vezes nos fazem tomar vias distintas, mobilizar uma complexa rede de enfoques até encontrar um lugar mais próximo de nós. Nos implicamos em uma posição de reflexividade constante, de negociação. Quando falamos de construcionismo falamos de muitos aspectos: problematizar por que vemos da forma como vemos, explicamos ou concebemos os aspectos sociais que permeiam nossas relações talvez seja um dos principais aportes. Implica também a não seguir uma única via linear, mas perceber que a todo momento nos são possibilitadas inúmeras alternativas e pontos de vista.

As narrativas produzidas pela investigação construcionista mobilizam aquilo que as metodologias exatas e/ou quantitativas não dariam conta, pois nossa linguagem é limitada: alcança apenas daquilo que constrói como signo, símbolo e significado socialmente, culturalmente e historicamente construídos, agenciados, negociados. Mas não abrange o universo que habita a mente humana em que são armazenadas imagens, sentidos próprios e significados particulares. O caráter autobiográfico, relacional e subjetivo consegue chegar a estes recôncavos habitados por referencias imagéticas oriundas de infinitas experiências porque ativa algo em nosso imaginário que não seria possível de outra maneira. É da ordem que afeta, que provoca. Configura-se como uma experiência inusitada para quem a experimenta. É a qualidade própria que o questionamento com sentido nos contempla ao tornar-se provocação investigativa, 
porque é isso que nos possibilita: mobilizar nossa experiência entre um antes e um depois de realizar uma pesquisa.

Outrossim, a perspectiva construcionista, contribui para problematizar a experiência estética e performática dos modos de ver no âmbito da formação de investigadores, pois permite ainda estabelecer alguns pontos relevantes: as relações da vida diária como construções sociais que se estabelecem a partir de relações de poder e intencionalidades; os fenômenos socioculturais acerca da pesquisa que configuram as construções imagéticas e alimentam concepções acerca da produção do conhecimento; as visões de mundo que são responsáveis por legitimar determinadas formas de atuar em detrimento de outras - neste caso, os modelos identitários que são construídos acerca da educação, da arte, e da pesquisa.

\section{Referências}

BRUNER, J. Actos de significado: más allá de la revolución cognitiva. Madrid: Alianza Editorial, 1991.

BERGER, P. \& LUCKMANN, T. The social construction of reality: a treatise in the sociology of knowledge. Garden City. Nova Iorque: Doubleday, 1966.

DELEUZE, G. y GUATTARI, F. Mil Platôs. Capitalismo e Esquizofrenia. Vol. 1. São Paulo: Editora 34, 1995.

GERGEN, K. Realidades y relaciones: aproximaciones a la construcción social. Espanha: Paidós, 1996.

GERGEN, K. Construir la realidad. Barcelona: Paidós, 2006.

HERNÁNDEZ, F. y RIFÁ, M. (Eds.) Investigación autobiográfica y cambio social. Barcelona: Octaedro, 2011.

HERNÁNDEZ, F. Catadores da cultura visual: proposta para uma nova narrativa Educacional, Porto Alegre: Ed. Mediação, 2007.

HOLSTEIN, J. A; GUBRIUM, J. F. Handbook of constructionist research. The Guilford Press New York and London, 2008.

IBÁÑEZ, T. Municiones para disidentes: realidad, verdad, política. Barcelona: Gedisa, 2001. 
IÑIGUEZ, L. La psicología social en la encrucijada postconstruccionista: historicidad, subjetividad, performatividad, acción. XII Encontro Nacional da ABRAPSO. Estratégias de I nvenção - A Psicologia Social no Contemporâneo. Porto Alegre: Brasil. 13,14, 15 de out. Pontifícia Universidade Católica do Rio Grande do Sul, 2003.

KINCHELOE, J. L. y BERRY K. S. Rigour and complexity in Education Research. Conceptualizing the Bricolage, Open University Press, New York, 2004.

VAN MANEN, M. Investigación educativa y experiencia vivida. Barcelona: Idea Books, 2003.

Lutiere Dalla Valle (UFSM/RS)

Doutorado (2012) e Mestrado (2009) em Artes Visuais e Educação: Um Enfoque Construcionista (Universitat de Barcelona/Espanha), Mestrado em Educação (Universidade Federal de Santa Maria, 2008). Especialização em Arte e Visualidade (Universidade Federal de Santa Maria/2005), Licenciatura Plena em Desenho e Plástica (2003) e Bacharelado em Desenho e Plástica (2002), ambos pela Universidade Federal de Santa Maria. Atualmente atua como Professor Adjunto no Departamento de Artes Visuais/ CAL/UFSM, Coordenador do Curso de Artes Visuais - Licenciatura e Bacharelado DAV/CAL/UFSM / e Programa de Pós-Graduação em Artes Visuais/PPGART - Linha de Pesquisa Arte e Cultura. Investiga as relações entre Artes Visuais, Cultura Visual e Construcionismo Social relacionado à formação de artistas e professores de artes visuais. Tem experiência na área de artes visuais, com ênfase em entornos educativos e metodologias de investigação. Líder do Grupo de Estudos e Pesquisas Artes Visuais e suas I/Mediações. Coordena o Projeto de Extensão, Núcleo Educativo Cláudio Carriconde CAL/UFSM. Membro pesquisador do GEPAEC - Grupo de Estudos e Pesquisas em Arte, Educação e Cultura/ UFSM. Endereço institucional: Universidade Federal de Santa Maria Centro de Artes e Letras/ Prédio 40. Sala 1225. Avenida Roraima, n. 1000. Cidade Universitária. Bairro Camobi. CEP 97105-900 Fone (55) 3220 8433. Endereço eletrônico: lutiere@dallavalle.net.br

Recebido em: 25/07/2014

Aprovado em: 08/08/2014 